\title{
Crosslinked Poly(ethylene oxide) as a Phase Transfer Catalyst in Reactions of $\mathrm{C}$ - and O-Alkylation
}

\author{
T. Tsanov, R. Stamenova, ${ }^{*}$ and C. Tsvetanov \\ Institute of Polymers, Bulgarian Academy of Sciences, \\ ul. Akad. Bontchev, bl. 103, 1113 Sofia, Bulgaria
}

(Received February 15, 1993)

\begin{abstract}
Gels of radiation crosslinked poly(ethylene oxide) (PEO) and modified with poly(ethyleneimine) PEO were used as highly active phase transfer catalysts in the alkylation of phenylacetonitrile with 1-bromobutane in the presence of aqueous potassium hydroxide. The reaction of alkylation was found to be second order reaction up to $40 \%$ conversion of phenylacetonitrile and the rate is proportional to the amount of added catalysts. The activity of the PEO gels has been studied as a function of the composition, degree of crosslinking and addition order of reagents. Modified with poly(ethyleneimine) PEO (up to $10 \mathrm{~mol} \%$ ) exhibited the highest catalytic activity. Ultrasound promotes extremely effective intermixing of the aqueous and organic phases resulting in greatly increased alkylation rate. The recovered catalysts could be re-used without decrease in activity.
\end{abstract}

KEY WORDS Crosslinked Poly(ethylene Oxide)/Crosslinked Poly(ethylene Oxide) Modified with Poly(ethyleneimine) / Phase Transfer Catalysts /

Quaternary salts are known as active phase transfer catalysts (PTC) for alkylation reactions in the presence of aqueous alkaline hydroxides. ${ }^{1-3}$ Alkylation of 2-phenylacetonitrile (PAN) with 1-bromobutane (BB) promoted by sodium hydroxide and a PTC is the first and mostly studied reaction. ${ }^{4,5}$ Makosza has studied in details the reaction in a two phase system with benzyltriethylammonium chloride (BTEA) and has suggested a mechanism including deprotonation at the interface, formation of ion pairs and succeeding migration of the ion pairs in the organic phase. Quaternary ammonium salts supported on crosslinked polystyrene of gel and macroporous type are active catalyst as well. ${ }^{6,7}$ Significant drawback of the quaternary salts is their susceptibility toward dequaternization by strong bases. The catalysts of polyether type unlike the quaternary salts are stable in alkali media and swell both in water and organic solvents. Regen et al. have found that poly(ethylene glycols) (PEG) grafted to crosslinked polystyrene support are remarkably active and stable catalysts for the alkylation of nitriles, ketones and alcohols. ${ }^{8}$ But grafting of PEG onto polystyrene support is a complicated and tedious process. Gel obtained by irradiation crosslinking of high molecular weight poly(ethylene oxide) has structure analogous to that of supported PEGs but its preparation is much easier. Though immobilized catalysts generally are less active than their soluble analogues, being easily separated from the reaction mixture and the possibility to be reused, they have good industrial prospects. It has been established in a previous paper that crosslinked PEO is an active PTC in nucleophilic substitution of alkyl halides with alkali cyanides. ${ }^{9}$ The present paper reports the results of studying the activity of radiation crosslinked high molecular weight PEO and modified PEO networks in the alkylation reaction of PAN with 1-bromobutane in 
the presence of aqueous $60 \%$ potassium hydroxide. The effect of different experimental parameters such as stirring.speed, degree of crosslinking, order of addition of reactants etc. on the reaction rate has been studied. The activity of crosslinked PEO in the alkylation of 1-octanol and cyclohexanol with 1-bromobutane has been also investigated.

\section{EXPERIMENTAL}

\section{Reagents}

All reagents are commercial products and are used without further purification: 2phenylacetonitrile (Fluka), 1-octanol (Fluka), cyclohexanol (Fluka), 1-bromobutane (Fluka), n-dodecane (Fluka), poly(ethyleleneimine), $50 \%$ aqueous solution (Fluka), 8-hydroxyquinoline (Fluka), 4,4'-dipyridyl $\cdot 2 \mathrm{H}_{2} \mathrm{O}$ (Fluka), dibenzo-18-crown ether-6 (Fluka), potassium hydroxide (Lachema, Czeho-Slovakia).

\section{Catalysts}

Crosslinked PEO was prepared by $\gamma$ irradiation from ${ }^{60} \mathrm{Co}$-source of degassed $2 \mathrm{wt} \%$ aqueous solutions of commercial PEO BADIMOL ${ }^{\mathrm{TM}}, M_{v}=2.5 \times 10^{6}$, (Neochim, Dimitrovgrad, Bulgaria). According to irradiation dose the gels were of different degree of crosslinking: $2 \mathrm{Mrad}$ (PEO-2), $4 \mathrm{Mrad}$ (PEO4), $5 \mathrm{Mrad}$ (PEO-6), $8 \mathrm{Mrad}$ (PEO-8), $10 \mathrm{Mrad}$ (PEO-10). The gels were washed three times with distilled water and freeze dried. Various modified networks were obtained by addition to the aqueous solutions of PEO following compounds: 8-hydroxyquinoline (HQ), 4,4'dipyridyl (DP), dibenzo- 18-crown ether-6 (18-C-6), and poly(ethyleneimine) (PEI). All solutions with modifiers were irradiated with total dose $2 \mathrm{Mrad}$. The gels were washed three times with ethanol and three times with distilled water and freeze dried. The gel particles are irregular in form and its size varies from 0.5 to $1 \mathrm{~mm}$. The composition of the modified networks was determined by elemental analysis
(Table I).

\section{General Procedures}

The experiments were carried out in a $10 \mathrm{ml}$ glass reactor. The temperature of the reaction vessel was maintained with a thermostat U-1 VEB Medingen, Germany. The reaction mixtures were mechanically stirred by a magnetic stirrer or by a ultrasonic disintegrator OD-20 Techpan (Poland). After the end of the reaction $4 \mathrm{ml}$ toluene, containing $n$-dodecane as internal standard and $8 \mathrm{ml}$ water were added. The mixture was vigorously stirred for $5 \mathrm{~min}$ and the organic layer was separated, dried over $\mathrm{CaCl}_{2}$ and analyzed by gas chromatograph "Carlo Erba," model Fractovap 4100 with a $25 \mathrm{~m}$-capillary. The filtered catalyst was washed with water and methanol and dried for reuse. The experiments with mechanical stirring yielded $98 \%$ recovered gel and those with ultrasound stirring $-96 \%$.

\section{Alkylation of PAN with 1-Bromobutane}

The reaction was carried out with different order of addition of reagents: 1) simultaneous addition, 2) direct addition, 3) reverse addition. In the simultaneous addition method the catalyst swelled $30 \mathrm{~min}$ in $2 \mathrm{ml} 60 \% \mathrm{KOH}$ at stirring speed $100 \mathrm{rpm}$ then $0.378 \mathrm{ml}(3.28$ mmol) PAN and $0.365 \mathrm{ml}(3.32 \mathrm{mmol}) 1-$ bromobutane were added and the stirring speed was adjusted. In the direct addition method the catalyst was conditioned in $2 \mathrm{ml}$ $60 \% \mathrm{KOH}$ and $0.365 \mathrm{ml} \mathrm{1-bromobutane} \mathrm{then}$ $0.378 \mathrm{ml}$ PAN was added at zero time. In the reverse addition method the catalyst swelled in $60 \% \mathrm{KOH}$ and $0.378 \mathrm{ml} \mathrm{PAN}$, and the addition of $0.365 \mathrm{ml} \mathrm{1-bromobutane} \mathrm{was} \mathrm{taken} \mathrm{as} \mathrm{a} \mathrm{start}$ of the reaction. At the end of the reaction the organic phase was analyzed by GLC. Analysis of the starting phenylacetonitrile and 1bromobutane showed no detectable impurities. Every GLC analysis was done twice and average values were used in calculations. Up to $60-70 \%$ conversion of PAN only monoalkylated product: $\alpha$-butylphenylacetonitrile 
was obtained. Above $70 \%$ conversion of PAN the dialkylated product: $\alpha, \alpha$-dibutylphenylacetonitrile was presented but its yield was limited to $3-5 \%$.

\section{Alkylation of 1-Octanol and Cyclohexanol with 1-Bromobutane}

In a typical run of alkylation of 1-octanol with 1-bromobutane the reaction vessel was charged with $0.63 \mathrm{ml}$ (4 mmol) 1-octanol, $0.86 \mathrm{ml}$ ( $8 \mathrm{mmol}$ ) 1-bromobutane, catalyst PEO-2, and $2 \mathrm{ml} 60 \%$ aqueous $\mathrm{KOH}$. After the mixture was stirred magnetically for $5 \mathrm{~h}$ $(400-500 \mathrm{rpm})$ at $35^{\circ} \mathrm{C}, 4 \mathrm{ml}$ methylene chloride and $8 \mathrm{ml}$ water were added, and the organic layer was then separated and dried $\left(\mathrm{Na}_{2} \mathrm{SO}_{4}\right)$ and analyzed by GLC. Analogous runs were carried out with cyclohexanol $(0.416 \mathrm{ml}, 4 \mathrm{mmol})$ at room temperature $\left(23^{\circ} \mathrm{C}\right)$ and $5 \mathrm{~h}$ reaction time. Only $n$-butyl $n$-octyl ether, respectively $n$-butyl cyclohexyl ether were registrated as reaction products.

\section{Swelling of Catalysts}

Dry PEO gel was weighed into a tared column with a fritted bottom. ${ }^{10}$ It was then soaked at room temperature for $48 \mathrm{~h}$ in the solvent. The excess liquid was removed by centrifugation for $10 \mathrm{~min}$ at $\times 1100 \mathrm{~g}$ and the swollen gel was then weighed.

\section{Reagents Composition in the PEO Gels}

A glass column with a fritted bottom was weighed together with dry crosslinked PEO $(22 \mathrm{mg}, 0.5 \mathrm{mmol})$. After adding 1-bromobutane $(1.8 \mathrm{ml}, 16.6 \mathrm{mmol})$, PAN (1.9 ml, 16.4 $\mathrm{mmol})$ and $60 \% \mathrm{KOH}(2 \mathrm{ml})$ the mixture was left to swell at shaking for $30 \mathrm{~min}$. After centrifugation the column with the swollen gel was weighed to obtain the total amount of imbibed constituents. The gel particles were washed twice with $3 \mathrm{ml}$ portions of toluene. The toluene solution was dried over anhydrous $\mathrm{Na}_{2} \mathrm{SO}_{4}$ and analyzed by GLC with $n$ dodecane as an internal standard. The amount of adsorbed aqueous $\mathrm{KOH}$ was calculated as a difference between the total weight of the swollen gel and the sum of the weights of PAN and $\mathrm{BB}$ and the dry gel.

\section{RESULTS AND DISCUSSION}

The immobilized catalysts based on highmolecular weight PEO were prepared by $\gamma$ irradiation of aqueous solutions of the linear polymer. The degree of crosslinking was controlled by the total dose. The modifiers 8-hydroxyquinoline, 4,4'-dipyridyl, dibenzo18-crown ether-6, and poly(ethyleneimine) of molecular weight $6.10^{5}-1.10^{6}$ (primary: secondary: tertiary amino groups $=1: 2: 1^{11}$ ) were added to the aqueous solution prior to the crosslinking. Incorporation of low-molecular-weight nitrogen-containing compounds is supposed to enhance catalytic activity due to the sinergetic effect between the oxyethylene active sites and the quaternary ammonium salts groups being obtained in situ. The same effect is expected for the crown ether units present in the polymer network. As seen from Table I only a part of the modifier is bound covalently in the network. No investigations have been carried out to check whether changes in the chemical structure of the modified compounds under irradiation occur.

Table I. Composition of modified PEO networks

\begin{tabular}{|c|c|c|c|c|}
\hline No. & Networks & $\begin{array}{l}\text { Mole } \\
\text { ratio } \\
\text { in } \\
\text { mixture }\end{array}$ & $\begin{array}{l}\text { Mole } \\
\text { ratio } \\
\text { in } \\
\text { network }\end{array}$ & Abbreviation \\
\hline 1 & $\begin{array}{c}\text { PEO-8-Hydro- } \\
\text { xyquinoline }\end{array}$ & $10: 1$ & $20: 1$ & PEO-HQ \\
\hline 2 & $\begin{array}{l}\text { PEO-4,4'-Di- } \\
\text { pyridyl }\end{array}$ & $10: 1$ & $40: 1$ & PEO-DP \\
\hline 3 & $\begin{array}{l}\text { PEO-Dibenzo- } \\
\text { 18-C-6 }\end{array}$ & $10: 1$ & $\sim 20: 1$ & PEO-18-C-6 \\
\hline 4 & $\begin{array}{l}\text { PEO-Poly(ethyl- } \\
\text { enimine) }\end{array}$ & $1: 1$ & $2.5: 1$ & PEO-PEI-2.5 \\
\hline 5 & $\begin{array}{l}\text { PEO-Poly(ethyl- } \\
\text { enimine) }\end{array}$ & $5: 1$ & $10: 1$ & PEO-PEI-10 \\
\hline
\end{tabular}


Table II. Monoalkylation of phenylacetonitrile with 1-Bromobutane ${ }^{a}$

\begin{tabular}{ll}
\hline \multicolumn{1}{c}{ PTC } & Yield $^{\mathrm{b}} \%$ \\
\hline- & $<2$ \\
PEO-2 & 56.0 \\
PEO-HQ & 17.7 \\
PEO-DP & 55.6 \\
PEO-18-C-6 & $68.2 ; 62.2^{\mathrm{c}}$ \\
PEO-PEI-10 & $78.7 ; 73.8^{\mathrm{c}}$ \\
PEO-PEI-2.5 & $74.9^{\mathrm{c}}$ \\
PEG (20000) & $42.1 ; 81.1^{\mathrm{d}}$
\end{tabular}

a Reaction of $3.28 \mathrm{mmol}$ PAN, $3.32 \mathrm{mmol} \mathrm{BB}$ and $0.57 \mathrm{mmol}$ PTC; $2 \mathrm{ml} 60 \%$ aqueous $\mathrm{KOH}$; conditioning $20 \mathrm{~min} ; T=30^{\circ} \mathrm{C} ; t=3 \mathrm{~h} ; 300 \mathrm{rpm}$; simultaneous addition of the organic reagents.

b GLC overall yield.

c With reused catalyst.

d Stirring, $600 \mathrm{rpm}$.

The PEO based networks are rather hydrophylic phase transfer catalysts. This factor plays favourable role in alkylation of 2-PAN in the presence of alkaline hydroxides according to the scheme:

$$
\mathrm{PhCH}_{2} \mathrm{CN}+\mathrm{HO}^{-} \rightleftharpoons \mathrm{PhC} \mathrm{CHCN}+\mathrm{H}_{2} \mathrm{O}
$$

$\mathrm{Ph} \overline{\mathrm{C}} \mathrm{HCN}+n-\mathrm{C}_{4} \mathrm{H}_{9} \mathrm{Br} \rightarrow$

$$
\mathrm{PhCH}\left(\mathrm{C}_{4} \mathrm{H}_{9}\right) \mathrm{CN}+\mathrm{Br}^{-}
$$

To compare the catalytic activity of the networks alkylation was carried out at stoichiometric ratio of the substrate and alkylbromide, and with equal quantity of the catalyst-ca. $17 \mathrm{~mol} \%$. Potassium hydroxide was preferred as a deprotonation base because linear polyethers have greatest complexation constants for potassium cation. ${ }^{12}$ Catalytic activity of the modified networks is compared in Table II. Linear polyether PEG-20000 is the most active catalyst under effective mass transfer ensured by vigorous stirring ( $>600$ $\mathrm{rpm})$. The effect of the modification is more pronounced when crown ether or a small amount of poly(ethyleneimine) $(<10 \mathrm{~mol} \%)$ is used. With increasing PEI content in the network to $30 \mathrm{~mol} \%$ its activity is significantly reduced. The network modified with 8 -hy-

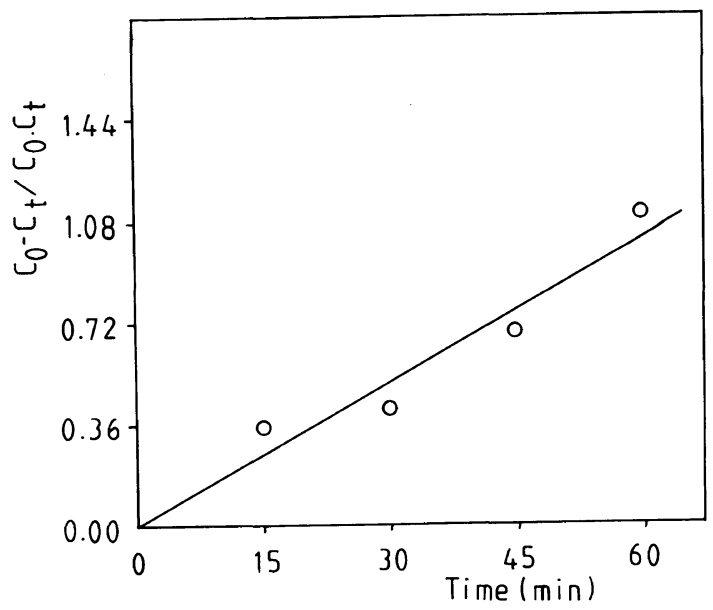

Figure 1. Reaction of PAN (3.28 mmol) with 1-bromobutane $(3.32 \mathrm{mmol})$ in the presence of cr-PED. $15 \mathrm{~mol} \%$ PEO-2; $2 \mathrm{ml} 60 \%$ aqueous $\mathrm{KOH} ; T=25^{\circ} \mathrm{C} ; 600 \mathrm{rpm}$; simultaneous addition of reagents.

droxyquinoline is also of lower activity. In both cases this effect could be explained by additional crosslinking contributed by the modifiers. As shown in Table II the networks PEO-2, PEO-18-C-6, and PEO-PEI-10 could be reused without any significant loss in activity. The effect of various factors on the catalytic activity has been studied only for crosslinked PEO and PEO modified with PEI.

\section{Kinetic Measurements}

Under the chosen conditions the reaction rate is of second order up to $40 \%$ conversion (Figure 1). The rate constant is $3.1 \times 10^{-5}$ $1 \mathrm{~mol}^{-1} \mathrm{~s}^{-1}$. Only the monoalkylated product was obtained under conversion of PAN up to $60-70 \%$ indicating high selectivity of the networks. According to the known mechanism ${ }^{7,13}$ the rate-limiting step is deprotonation of $\mathrm{C}-\mathrm{H}$ acid, occurring on the interface boundary. The next reaction of the carbanion with 1-bromobutane proceeds very fast. If mass transfer and intraparticle diffusion are eliminated as limiting factors, the reaction rate is mainly determined by the ability of the active sites to transfer potassium salt of PAN monoanion 


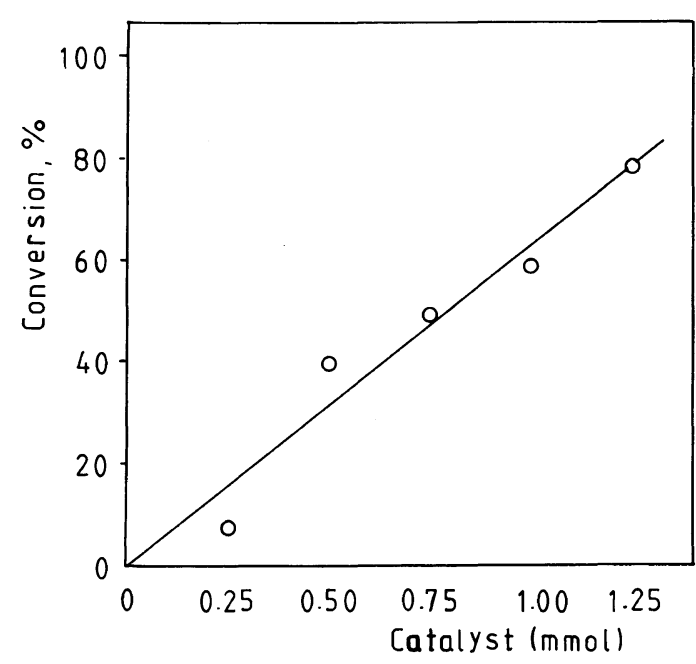

Figure 2. Conversion of PAN as a function of catalyst amount. Catalyst: PEO-2; reaction of $3.28 \mathrm{mmol}$ PAN, $3.32 \mathrm{mmol} \mathrm{BB}, 2 \mathrm{ml} 60 \%$ aqueous $\mathrm{KOH}$; conditioning $20 \mathrm{~min} ; \quad T=30^{\circ} \mathrm{C}$; without stirring; simultaneous addition.

from the interface to the organic phase. Reaction rate being linearly dependent on the catalyst amount (Figure 2) proves that the same mechanism is also valid for reactions when crosslinked PEO is used as a catalyst.

\section{Effect of Crosslinking Density and Stirring Speed}

The effect of crosslinking density and stirring speed on the ability of crosslinked PEO to promote the alkylation of PAN is demonstrated in Table III. The feaction rate lowered with increasing the dose, corresponding to the crosslinking density: The only exception is the network obtained with irradiation dose of $10 \mathrm{Mrad}$ which is highly active. The degree of crosslinking affects the swelling capacity of the gel and accordingly diffusion processes inside the particles. Near to the crosslinks conformational freedom is quite hindered and complexation is not possible. Increasing the number of crosslinks results in lowering the effective concentration of active sites. On the other hand gels of crosslinked PEO are known as very loose-average length of the segment in
Table III. Effect of crosslinking density and stirring speed on catalytic activity of cr-PEO ${ }^{\mathrm{a}}$

\begin{tabular}{cccc}
\hline & \multicolumn{3}{c}{ Yield $^{\mathrm{b} / \%}$} \\
\cline { 2 - 4 } $\begin{array}{c}\text { Mose } \\
\text { Mrad }\end{array}$ & $\begin{array}{c}\text { Without } \\
\text { stirring }\end{array}$ & $300 \mathrm{rpm}$ & Ultrasound \\
& - & - & 25.9 \\
- & 5.8 & 18.1 & 97.0 \\
0 & & & \\
$($ PEG-20000) & 39.8 & 46.0 & 99.8 \\
2 & 19.8 & 18.8 & - \\
4 & 16.7 & 13.8 & 69.8 \\
5 & 15.7 & 15.7 & - \\
6 & 15.4 & 16.2 & - \\
8 & 52.1 & 47.7 & 94.2 \\
10 & & &
\end{tabular}

a Reaction of $3.28 \mathrm{mmol}$ PAN, $3.32 \mathrm{mmol} \mathrm{BB}, 0.5 \mathrm{mmol}$ PTC, and $2 \mathrm{ml} 60 \%$ aqueous $\mathrm{KOH}$; conditioning $20 \mathrm{~min} ; \quad T=30^{\circ} \mathrm{C} ; \quad t=2 \mathrm{~h} ; 300 \mathrm{rpm} ;$ simultaneous addition of reagents.

b GLC overall yield.

networks obtained by irradiation of 2 to $10 \mathrm{Mrad}$ varies in the range $5000-2000 .^{14}$ This suggests great permeability of the gel towards reagents and access to the active sites. So the reaction is retarded more likely because of the decreased effective concentration of the oxyethylene segments involved in the phase transfer than of the growing control of the intraparticle diffusion. As to the network obtained with a dose $10 \mathrm{Mrad}$ significant structural changes might occur due to the great quantity of absorbed energy. More intense chain scission results in formation of many segments with free ends. They have better solving ability compared with the segments between two crosslinks what means a new increase of the effective concentration of the active sites. Table III shows that alkylation rate does not depend on the mechanical stirring. This suggests that using crosslinked PEO as a PTC neither intramolecular diffusion nor mass transfer are rate-limiting factors. Obviously the aqueous and organic phases are well absorbed by the gel and they are favorably distributed between the gel and the external 
Table IV. Effect of method of addition on rate of alkylation of PAN ${ }^{\mathrm{a}}$

\begin{tabular}{|c|c|c|c|c|c|c|c|c|}
\hline \multirow{3}{*}{ PTC } & \multirow{2}{*}{\multicolumn{2}{|c|}{$\begin{array}{l}\text { Euilibrium } \\
\text { swelling in }\end{array}$}} & \multicolumn{6}{|c|}{ Yield $/ \%$} \\
\hline & & & \multicolumn{3}{|c|}{$60 \%$ aq $\mathrm{KOH}$} & \multicolumn{3}{|c|}{$50 \%$ aq. $\mathrm{KOH}$} \\
\hline & $\mathrm{BB}$ & PAN & $\mathrm{DA}$ & RA & SA & DA & RA & SA \\
\hline PEO-2 & 3.6 & 20.9 & 50.5 & 75.1 & 41.4 & 15.9 & 18.3 & 7.3 \\
\hline PEO-PEI-10 & 2.8 & 13.0 & 58.6 & 38.1 & 48.0 & 20.4 & 18.9 & 14.6 \\
\hline PEO-PEI- 2.5 & - & - & - & - & - & 10.6 & 5.8 & 14.0 \\
\hline
\end{tabular}

RA, reverse addition; DA, direct addtion; SA, simultaneous addition.

${ }^{a}$ Reaction of $3.28 \mathrm{mmol}$ PAN, $3.32 \mathrm{mmol} \mathrm{BB}, 0.56 \mathrm{mmol}$ PTC, $2 \mathrm{ml}$ aqueous $\mathrm{KOH} ; T=30^{\circ} \mathrm{C} ; t=1.5 \mathrm{~h} ; 300 \mathrm{rpm}$.

b GLC overall yield.

media. As PEO is soluble both in water and organic phase, especially in aromatic nitrile, large interface boundary is formed in the gel. This is the main reason for the high activity of PEO as PTCs. Unlike the mechanical stirring ultrasound mixing greatly affects the alkylation rate. Alkylation of PAN with polystyrene-supported BTMA as a catalyst is zero using ultrasonic stirring despite of the observed emulgation of the system and this fact was not explained. ${ }^{8}$ In the presence of crosslinked PEO ultrasound efficiency is related to the oxyethylene structure favouring formation of much finer dispersions of the organic phase. The gel isolated affer the reaction with ultrasound stirring does not lose weight and keeps its activity when reused.

\section{Effect of Addition Order of Reagents and Swelling}

Ford et al. have observed alkylation rate of PAN with 1-bromobutane to be strongly dependent on the order of addition of reagents. ${ }^{6,7,15}$ Remarkable rate differences are obtained simply by changing the order of addition of reagents to the reaction mixture: the reverse addition method gives a rate constant 8 times greater than the direct addition method. The dependence of rate on the order of addition of reagents is attributed to the greatly different abilities of PAN and 1-bromobutane to swell the catalyst. Tables IV
Table V. Effect of catalyst conditioning on the rate of alkylation of PAN $^{\text {a }}$

\begin{tabular}{|c|c|c|c|c|}
\hline \multirow{2}{*}{ PTC } & \multirow{2}{*}{$\begin{array}{c}\text { Time of } \\
\text { conditioning } / \mathrm{h}\end{array}$} & \multicolumn{3}{|c|}{ Yield $^{b} / \%$} \\
\hline & & DA & RA & SA \\
\hline PEO-2 & 0.5 & 15.9 & 18.3 & 7.3 \\
\hline PEO-2 & 3.0 & 14.9 & 17.0 & 5.8 \\
\hline PEO-PEI-10 & 0.5 & 20.4 & 18.9 & 14.6 \\
\hline PEO-PEI-10 & 3.0 & 20.6 & 12.0 & 13.8 \\
\hline PEO-PEI-2.5 & 0.5 & 10.6 & 5.8 & 14.0 \\
\hline PEO-PEI-2.5 & 1.5 & 25.0 & 9.6 & 15.2 \\
\hline PEO-PEI-2.5 & 3.0 & 22.0 & 10.0 & 14.7 \\
\hline
\end{tabular}

DA, direct addition; RA, reverse addition; SA, simultaneous addition.

a Conditions as in Table IV; $2 \mathrm{ml} 50 \%$ aqueous $\mathrm{KOH}$.

b GLC overall yield.

and $\mathrm{V}$ show the correlation between the reaction rate and the order of addition of PAN and BB for the three types of PTC: PEO-2 and two PEO-PEI of different mole ratio. Maximum rate for the reaction with PEO-2 as a PTC is reached in reverse addition method: preliminary swelling with PAN and aqueous $\mathrm{KOH}$; and minimum rate-in simultaneous addition of PAN and BB: preliminary swelling only with aqueous $\mathrm{KOH}$. To explain this correlation in Table VI are given data for the distribution of the reagents in a network swollen for $1 \mathrm{~h}$. Oxyethylene chains swell extremely in PAN (Table IV). In reverse addition method the network swells in two 
Table VI. Amount of imbibed reagents in swollen PEO gels under two- and three-phase conditions at room temperature

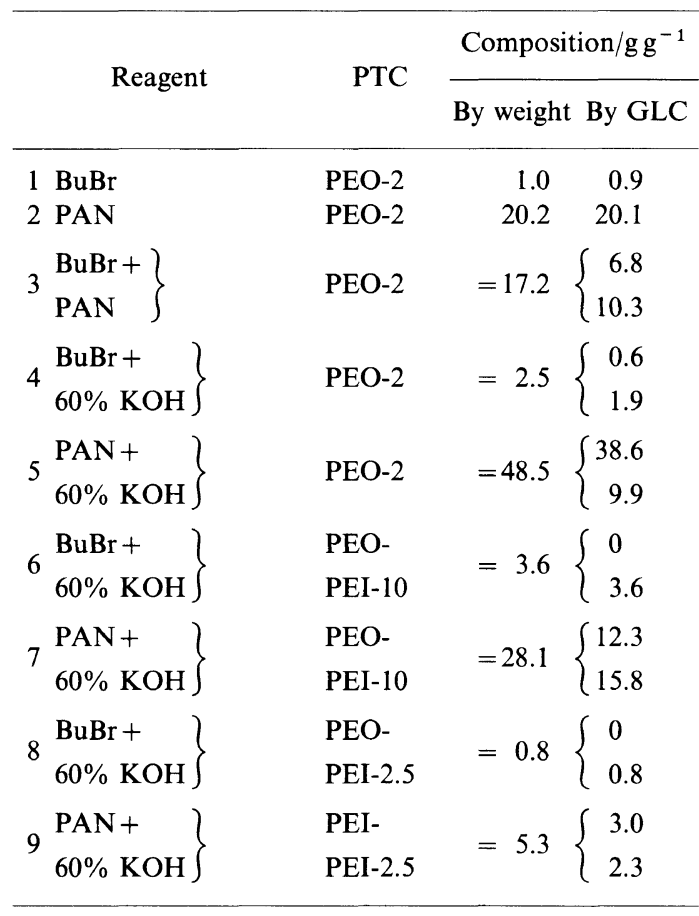

phase medium: PAN and aqueous $\mathrm{KOH}$. It is able to absorb quickly a preat amount of the two phase, thus large interface is formed. Deprotonation of the organic substrate by the hydroxyl anions takes place and the formed ionic pairs are solvated by the catalytic sites, allowing their transfer in the organic phase, i.e., in the very substrate PAN. The next fast reaction step -interaction with the carbanions starts immediately after the addition of the alkylation agent BB. In the direct addition method the network is previously swollen in a mixture of $\mathrm{BB}$ and aqueous $\mathrm{KOH}$. The slower reaction rate is due to much less swelling in $\mathrm{BB}$ and to the time necessary for PAN to penetrate inside the network. The lowest alkylation rate with simultaneous addition of reagents after preliminary swelling of PEO-2 in aqueous $\mathrm{KOH}$ is due to the preferred PAN absorption. Thus the migration of 1-bromobutane from the outer media into the network is hindered.
In the case of the PEO-PEI networks the effect of the order of addition of reagents is inverse. The rate is the highest in direct addition method and the lowest in the reverse addition method. PEO-PEI-10 and PEO-PEI2.5 swell less in the two reagents (Tables IV and VI) most probably because of their additionally crosslinking by intermolecular hydrogen bonds. Incorporation of greater amount of polyethyleneimine into the network might be a reason for denser crosslinking during the $\gamma$-irradiation. This is proved by the reduced equilibrium swelling in distilled water: PEO-2 - 24.6; PEO-PEI-10-18.7; PEO-PEI2.5-12.1. In direct addition method PEO-PEI10 has the greatest catalytic activity (Table IV). The preliminary swelling with 1-bromobutane and aqueous $\mathrm{KOH}$ is accompanied by in situ quaternary ammonium salt formation. The presence of oxyethylene chains in close vicinity is presumed to cause their additional activation. Some amount of BB is consumed by the quaternization but this is compensated by the enhanced catalytical activity. As a result PEO-PEI-10 is a more active than PEO-2 in both case of direct and reverse addition of reagents (Tables IV and V). As seen from Table VI BB was not detected in the GLC analysis of swollen in two phase medium for $1 \mathrm{~h}$ PEO-PEI-10 network corresponding to direct addition. Therefore the equilibrium swelling is reached rather slow (Table IV). The small amount $\mathrm{BB}$ absorbed during the $1 \mathrm{~h}$ reacts with the amino groups and no free BB is observed. After the addition of the substrate the reaction proceeds much faster because of the markedly higher activity of the quarternized groups. While in the case of reverse addition it is realized only solvation of the ionic pair $\mathrm{R}^{+} \mathrm{PAN}^{-}$by the oxyethylene units and amino groups. Due to consumption of the alkylating reagent $\mathrm{BB}$ in the faster reaction with carbanion it cannot yield measurable amount of quaternary alkylammonium ions. When PEO-PEI-2.5 is used, the reaction rate is lower in the three methods of addition of reagents 
(Table IV). As seen from Table VI swelling is considerably less and intraparticle diffusion also controls the rate. Only in simultaneous addition method of the reagents diffusion limitation is overtaken by more significant quaternization and consequently higher catalytic activity.

Table $\mathrm{V}$ shows the effect of the time of conditioning on the alkylation rate in different addition methods. PEO-2 and PEO-PEI-10 reach maximum swelling for $30 \mathrm{~min}$ and rate does not change with further conditioning. The network containing greater amount of PEI reaches its highest activity in the direct and reverse addition method after three times longer conditioning. In the direct addition method preliminary swelling for a long time in $\mathrm{BB}$ results in more complete quaternization and enhenced catalytic activity of PEO-PEI-2.5. In reverse addition method the long duration of conditioning ensures maximum swelling thus eliminating partly the effect of the diffusion as a rate-limiting factor. Only in the case of simultaneous addition the reaction rate does not depend on the conditioning time. The greater swelling of PEO-PEI-2.5 in PAN and the presence of the $\mathrm{BB}$ reduce the role of intraparticle diffusion and enhance its activity because of quaternization. The comparison of the results in Tables IV, V, and VI suggests that preliminary quaternized PEO-PEI-10 should possess maximum catalytic activity. It contains less polyethyleneimine so the swelling capacity is not greatly reduced but sufficient to enhance the catalytic activity by quaternization.

\section{Alkylation of Alcohols}

High catalytic activity of crosslinked PEO is further demonstrated in Table VII by the successful alkylation of aliphatic and cyclic alcohols. The results of Regen et al. achieved with polystyrene-supported PEGs $^{8}$ (16 oxyethylene units) are also shown in Table VII for comparison. Alkylation of 1-octanol yielding over $90 \%$ conversion was carried out
Table VII. Alkylation of 1-octanol and cyclohexanol with 1-bromobutane in the presence of $60 \%$ aqueous $\mathrm{KOH}$ catalyzed by $\mathrm{PEO}-2$

\begin{tabular}{|c|c|c|c|}
\hline \multirow{2}{*}{ PTC } & \multirow{2}{*}{ Substracte } & \multirow{2}{*}{$\begin{array}{c}\text { Catalyst } \\
\text { amount } \\
\text { in mol\% } \\
{[\mathrm{EO}]}\end{array}$} & Yield $^{\mathrm{a}}$ \\
\hline & & & $\%$ \\
\hline Grafted PEG & 1-Octanol ${ }^{b}$ & 80.0 & 79.0 \\
\hline PEO-2 & 1-Octanol ${ }^{\mathrm{b}}$ & 6.25 & 76.0 \\
\hline PEO-2 & 1-Octanol ${ }^{\mathrm{b}}$ & 12.5 & 90.1 \\
\hline PEO-2 & 1-Octanol ${ }^{\mathrm{b}}$ & 25.0 & 91.0 \\
\hline Grafted PEG & Cyclohexanol $^{\mathrm{c}}$ & $80.0(16 h)$ & 77.0 \\
\hline PEO-2 & Cyclohexanol $^{\mathrm{c}}$ & $12.5(5 \mathrm{~h})$ & 53.3 \\
\hline
\end{tabular}

a GLC overall yield.

b Reaction of $4 \mathrm{mmol} 1$-octanol, $8 \mathrm{mmol} \mathrm{BB}, 2 \mathrm{ml} \mathrm{60 \%}$ aq KOH; $T=35^{\circ} \mathrm{C} ; t=5 \mathrm{~h} ; 400 \mathrm{rpm}$.

c Reaction of $4 \mathrm{mmol}$ cyclohexanol, $8 \mathrm{mmol} \mathrm{BB}, 2 \mathrm{ml}$ $60 \%$ aq $\mathrm{KOH} ; T=23^{\circ} \mathrm{C} ; 400 \mathrm{pm}$.

in the presence of 6 times smaller amount of PEO-2 than that of grafted PEG. Under the same conditions for alkylation of cyclohexanol 3 times less catalyst and time are enough to reach conversion over $70 \%$.

In conclusion, the rate of nucleophilic displacement reactions promoted by hydroxide ions is as much higher as the hydrophylic character of the phase transfer catalyst is more pronounced. So crosslinked PEO is much more effective in the alkylation of nitriles, alcohols, etc. Having also in mind its other advantages as stability in alkali media, sufficient mechanical strength, recycling and reusability, lower price, crosslinked PEO obtained by $\gamma$-irradiation has greatest synthetic utility for alkylation in the presence of alkaline hydroxides.

Acknowledgments. The authors gratefully acknowledge the financial support of this research by National Science Foundation through Grant No. X-30.

\section{REFERENCES}

1. M. Makosza, Pure Appl. Chem., 43, 439 (1975).

2. W. P. Weber and G. W. Gokel, "Phase Transfer 


\section{Crosslinked PEO as PTC for C- and O-Alkylation}

Catalysis in Organic Synthesis," Springer-Verlag, New York, 1977.

3. E. W. Dehmlow and S. S. Dehmlow, "Phase Transfer Catalysis," Verlag Chemie, Weinheim/Bergstr., Germany, 1980.

4. J. C. Jarrouse and R. Hebd, Seances Acad. Sci., Ser. C, 232, 1424 (1951).

5. M. Makosza and A. Jonczyk, Org. Synth., 55, 91 (1976).

6. T. Balakrishnan and W. T. Ford, J. Org. Chem., 48, 1029 (1983).

7. T. Balakrishnan, S. Hari Babu, and A. Perumal, $J$. Polym. Sci., A, Polym. Chem., 28, 1421 (1990).

8. W. Kimura, P. Kirszensztejn, and S. L. Regen, J. Org. Chem., 48, 385 (1983).

9. T. Tsanov, R. Stamenova and C. Tsuethanov,
Polymer, 34, 616 (1993).

10. J. Stamberg and S. Sevcik, Collect. Czech. Chem. Commun., 31, 1009 (1966).

11. L. E. Davis, "Water-Soluble Resins," R. L. Davidson and M. Sittig, Ed., Reinhold, New York, 1968, p 216.

12. M. Tomoi and W. T. Ford, "Syntheses and Separations Using Functional Polymers," D. C. Sherrington and P. Hodge Ed., John Wiley \& Sons, New York, 1988, p 182.

13. W. T. Ford and M. Tomoi, Adv. Polym. Sci., 55, 49 (1984).

14. L. Minkova, R. Stamenova, C. Tsvetanov, and E. Nedkov, J. Polym. Sci., Polym. Phys. Ed., 27, 621 (1989).

15. T. Balakrishnan and W. T. Ford, Tetrahedron Lett., 22, 4377 (1981). 